\title{
Histopathological Profile of Benign Colorectal Diseases in Al- Madinah Region of Saudi Arabia
}

\author{
Abdulkader Mohammed Albasri
}

\begin{abstract}
Background: Patients with long-standing inflammatory bowel disease (IBD) have an increased risk of developing colorectal cancer (CRC). Colon cancer risk in IBD increases with longer duration and greater anatomic extent of colitis, the presence of primary sclerosing cholangitis, family history of CRC and degree of inflammation of the bowel. This study aimed to characterize the histopathological pattern of benign colorectal diseases among Saudi patients and to highlight age and gender variations of lesions as base line data for future studies to investigate the link between benign / IBD and colorectal cancers in the local population. Materials and Methods: The materials consisted of 684 biopsies, reported as benign (excluding malignancies and polyps) at the Department of Pathology, King Fahad Hospital, Madinah, Saudi Arabia from January 2006 to December

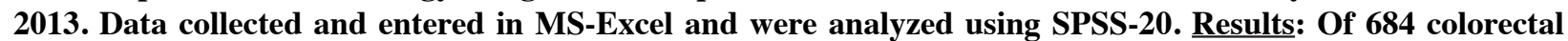
tissues reviewed, 408 specimens $(59.6 \%)$ were from male patients and 276 specimens $(40.4 \%)$ were from females giving a male: female ratio of 1.5:1. Age of the patients ranged from 4 to 75 years with a mean of 39.6 years. The most frequent histologic diagnosis was a chronic non specific proctocolitis followed by ulcerative colitis, accounting respectively for $\mathbf{5 2 . 6 \%}$ and $31.7 \%$ of all cases. These were followed by Crohn's disease $22(3.2 \%)$, ischemic bowel disease $20(2.9 \%)$, diverticular disease $14(2 \%)$, eosinophilic colitis $12(1.7 \%)$ and solitary rectal ulcer $12(1.7 \%)$. A minority of 21 patients $(3.1 \%)$ were cases of acute nonspecific proctocolitis, schistosomiasis,

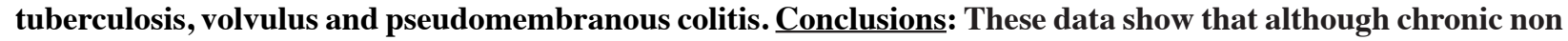
specific proctocolitis and ulcerative colitis were the dominant diagnoses, Crohn's disease, ischemic bowel disease and diverticular disease also existed to a lesser extent and should be considered in the differential diagnosis of benign colorectal diseases. This study provides a base line data for future studies which would be taken up to investigate the link between benign / IBD and colorectal cancers in the local population.
\end{abstract}

Keywords: Benign colorectal diseases - histopathology - Al-Madinah - Saudi Arabia

Asian Pac J Cancer Prev, 15 (18), 7673-7677

\section{Introduction}

Large bowel diseases are very common throughout the world, especially in the developing countries. These are mainly due to microbial infections which are treated at the primary care level; however the chronic disorders are referred to specialist centres, where endoscopic examinations are performed, along with histological evaluation. Large bowel biopsies account for about one quarter to one third of the histopathologist's work-load varying from centre to centre. In the past, while colorectal cancer (CRC) and inflammatory bowel diseases (IBD) accounted for most common large bowel diseases in the western countries; recent observations and research suggest that more and more of these 'western' diseases are being diagnosed in the developing countries (Molodecky et al., 2012; Adams \& Bornemann, 2013; Ponder \& Long, 2013; Zhao et al., 2013).

Reviewing the recent (last five years' literature) regarding IBD, there is abundant scientific material on epidemiology and related parameters from the Western and developed world (Lakatos et al., 2011; Mangat et al., 2011; Achitei et al., 2013; Klarin et al., 2013; Penn et al., 2013; Burisch., 2014; Busch et al., 2014; Golovics et al., 2014, Ko et al., 2014; Nguyen et al., 2014; Norgard et al., 2014). Asian scientists have contributed to IBD literature significantly suring the last five years (Ahuja \& Tandon, 2010; Al-Jashamy et al., 2010; Ren \& Fang, 2011; Ng et al., 2013; Wei et al., 2013; Zeng et al., 2013; Huai et al., 2014; Kasturiratne et al., 2014). Similarly, the researchers of KSA and surrounding regions have also submitted their share in the recent literature as reviews and original research articles on various topics and epidemiological aspect of IBD (Khawaja \& Sawan, 2009; Siddique et al., 2012; Al-Mofarreh \& Al-Mofleh, 2013; Ghosh et al., 2013; Safarpour et al., 2013; Esmat et al., 2014; Mosli et al., 2014). Articles on diverticular disease (Azzam et al., 2013; Faucheron et al., 2013); and schstosomiasis (Liu et 
al., 2013; Soliman et al., 2014) are also available in the recent literature.

Finally, there are a few articles in the recent literature on the spectrum / pattern of large diseases based on colonoscopic biopsies, from Nepal (Rajbhandari et al., 2013); Peru (Villafuerte-Galvez et al., 2012), Nigeria (Alatise et al., 2012), Pakistan (Ahmad et al., 2013), and KSA (Qayyum \& Sawan, 2009).

Extensive literature search reveal no scientific publication on large bowel diseases from the Al-Madinah Al- Munawwarah region of KSA; except for two recent articles on colorectal polyps (Albasri et al., 2014a) and colorectal cancer (Albasri et al., 2014b). Thus our study would be the first of its kind, addressing the spectrum of benign large bowel disease as diagnosed in Al-Madinah Al- Munawwarah, KSA. This study would provide a baseline data for future studies which would be taken up to investigate the link between benign / inflammatory colorectal diseases and CRC in the local population.

\section{Materials and Methods}

This retrospective study included all biopsies which were reported as benign (excluding malignancies and polyps) at King Fahad Hospital, Madinah, Saudi Arabia between January 2006 and December 2013. Histopathology slides of cases within the study period were reviewed by the author to make a consensus diagnosis. Data including patients' age, sex and endoscopic findings were recorded in a tabulated form. Confirmatory histologic features of chronic proctocolitis included some or all of the features of: crypt distortion, cryptitis, mucin depletion, Paneth cell metaplasia and chronic inflammatory infiltrate, preferably at the base of the crypts. Patients having such features were considered to have inflammatory bowel disease, consistent with ulcerative colitis. Presence of granuloma in mucosal biopsies raised the possibility of Crohn's disease. However its absence did not preclude the diagnosis. Presence of bilharzial ova in biopsies was considered confirmatory of schistosomiasis. Cases where there is only an increase in mononuclear and acute inflammatory cells but with normal architecture and no other histological evidence of inflammatory bowel disease, bilharzial ova or features to indicate ischaemia, neoplasia or other diagnostic entity, were labeled as nonspecific proctocolitis, or acute selflimited colitis. In cases otherwise, where no abnormality was noted a diagnosis of normal colonic mucosa was made. Statistics were computed using SPSS version 20 (SPSS Inc. Chicago, IL).

\section{Results}

A total of 684 colorectal specimens were reported as benign (excluding malignancies and polyps) at the Department of Pathology, King Fahad Hospital, Madinah, Saudi Arabia from January 2006 to December 2013. Of the reviewed cases, 408 specimens $(59.6 \%)$ were from male patients and 276 specimens $(40.4 \%)$ were from female patients giving a male: female ratio of 1.5:1. Age of the patients ranged from 4 to 92 years with a mean age 39.6 years. The majority of the benign colorectal diseases $(n=443 ; 64.8 \%)$ were seen in the age group $21-50$ years. The young age group ( $\leq 20$ years) and the elderly age group above 60 years constituted $10.2 \%$ and $13.6 \%$ respectively. Table 1 demonstrates the overall distribution of different benign colorectal diseases distributed among males and females patients.

The diagnosis of chronic non specific proctocolitis was predominant, seen in 360 patients amounting to $52.6 \%$ of all cases (Table 1). Of these cases $239(66.4 \%)$ were males; while 121 (33.6\%) were females with a male: female ratio 1.9:1. Most of the patients $(n=230 ; 63.9 \%)$ were between 21-50 years of age (Table 2). Two hundred and seventeen $(31.7 \%)$ patients satisfied the diagnostic clinicopathological criteria of ulcerative colitis, with an age range between 12 and 92 years (mean 37.7 years). One hundred and twenty $(55.3 \%)$ cases were male; while $97(44.7 \%)$ were females with a male: female ratio 1.2:1.

Table 1. Mean age and Istribution of 684 Patients with Colorectal Lesions

\begin{tabular}{lrrr}
\hline Histological Diagnosis & No. $(\%)$ & M/F & $\begin{array}{c}\text { Mean } \\
\text { ageye`ars }\end{array}$ \\
\hline Chronic non specific proctocolitis & $360(52.6)$ & $239 / 121$ & 41.7 \\
Ulcerative colitis & $217(31.7)$ & $120 / 97$ & 37.7 \\
Crohn's disease & $22(3.2)$ & $10 / 12$ & 27.1 \\
Ischemic bowel disease & $20(2.9)$ & $10 / 10$ & 62.1 \\
Diverticular disease & $14(2.2)$ & $10 / 04$ & 61.5 \\
Eosinophilic colitis & $12(1.8)$ & $9 / 3$ & 47.3 \\
Solitary rectal ulcer & $12(1.8)$ & $6 / 6$ & 43.9 \\
Acute nonspecific proctocolitis & $9(1.3)$ & $5 / 4$ & 41 \\
Schistosomiasis & $6(0.8)$ & All Male & 31.5 \\
Tuberculosis & $2(0.3)$ & $01 / 01$ & 29.5 \\
Volvulus & $2(0.3)$ & Both Male & 34.5 \\
Pseudomembranous colitis & $2(0.3)$ & Both Male & 56 \\
Normal colrectal mucosa & $6(0.8)$ & $4 / 2$ & 46.5 \\
TOTAL & $684(100)$ & & \\
\hline
\end{tabular}

Table 2. Age Distribution of 684 Patients with Colorectal Lesions

\begin{tabular}{|c|c|c|c|c|c|c|c|}
\hline \multicolumn{8}{|c|}{ Histological diagnosis } \\
\hline & $\leq 20$ & $21-30$ & $31-40$ & $41-50$ & $51-60$ & $>60$ & Total \\
\hline \multicolumn{8}{|c|}{ Chronic non specific proctocolitis } \\
\hline & 33 & 85 & 61 & 84 & 46 & 51 & 360 \\
\hline \multicolumn{8}{|c|}{ Ulcerative colitis } \\
\hline & 26 & 56 & 58 & 42 & 20 & 15 & 217 \\
\hline \multicolumn{8}{|c|}{ Crohn's disease } \\
\hline & 8 & 8 & 6 & 0 & 0 & 0 & 22 \\
\hline \multicolumn{8}{|c|}{ Ischemic bowel disease } \\
\hline & 2 & 0 & 1 & 2 & 2 & 13 & 20 \\
\hline \multicolumn{8}{|c|}{ Diverticular disease } \\
\hline & 0 & 0 & 2 & 2 & 1 & 9 & 14 \\
\hline \multicolumn{8}{|c|}{ Eosinophilic colitis } \\
\hline & 0 & 1 & 4 & 2 & 3 & 2 & 12 \\
\hline \multicolumn{8}{|c|}{ Solitary rectal ulcer } \\
\hline & 0 & 4 & 1 & 5 & 0 & 2 & 12 \\
\hline \multicolumn{8}{|c|}{ Acute nonspecific proctocolitis } \\
\hline & 0 & 4 & 2 & 0 & 2 & 1 & 9 \\
\hline \multicolumn{8}{|c|}{ Schistosomiasis } \\
\hline & 1 & 2 & 1 & 2 & 0 & 0 & 6 \\
\hline \multicolumn{8}{|c|}{ Tuberculosis } \\
\hline & 0 & 2 & 0 & 0 & 0 & 0 & 2 \\
\hline \multicolumn{8}{|c|}{ Volvulus } \\
\hline & 0 & 1 & 0 & 1 & 0 & 0 & 2 \\
\hline \multicolumn{8}{|c|}{ Pseudomembranous colitis } \\
\hline & 0 & 0 & 0 & 0 & 2 & 0 & 2 \\
\hline \multicolumn{8}{|c|}{ Normal colorectal mucosa } \\
\hline & 0 & 0 & 2 & 2 & 2 & 0 & 6 \\
\hline Total & 70 & 163 & 138 & 142 & 78 & 93 & 684 \\
\hline
\end{tabular}


Most of the patients $(\mathrm{n}=156 ; 71.9 \%)$ were between $21-50$ years of age; whereas only $11.9 \%$ were under 20 years and $16.1 \%$ were above the age of 50 years (Table 2). Twenty two cases of Crohn's disease were found, representing $3.2 \%$ of all lesions. The disease was slightly more common in females than males; with a female: male ratio $1.2: 1$. The age of the patients ranged between 15 and 40 years with mean age of 27.1 years at time of diagnosis. Most of the patients $(n=16 ; 72.7 \%)$ were seen in the first three decades of life (Table 2). Ischemic bowel disease and diverticular disease were seen in 20 and 14 patients amounting to $2.9 \%$ and $2.2 \%$ of all cases respectively (Table 1). The male: female ratios were $1: 1$ and 2.5:1 with mean age of 62.1 years and 61.5 years respectively. Other less common conditions were eosinophilic colitis and solitary rectal ulcer, seen in $12(1.8 \%)$ cases both. The male: female ratios were $3: 1$ and $1: 1$ with mean age of 47.3 years and 43.9 years respectively.

\section{Discussion}

Large bowel diseases are quite common throughout the world. Neoplastic conditions and IBD are considered to be more common in the Western developed world, in contrast to infections and other non-specific conditions being prevalent in the developing countries. However the recent literature suggests a change in the trend. The diseases of developed world (neoplastic conditions and IBD) are showing an increase in the incidence and prevalence in the developing countries as well (Molodecky et al., 2012; Adams \& Bornemann, 2013; Ponder \& Long, 2013). We have already published articles on the colorectal polyps and colorectal cancers in the region of Al-Madinah Al-Munawwarah (Albasri et al., 2014a; Albasri et al., 2014b); we are now sharing our work in the benign colorectal diseases.

We reviewed a total of 684 benign biopsies, having male: female ratio of $1.5: 1$; we will compare these figures with similar studies in the recent literature. The male to female ratio was 1.4:1 in a study of 126 colorectal biopsies from Nepal (Rajbhandari et al., 2013). A Nigerian study, in their series of 320 patients found a male to female ratio of 1.3:1 (Alatise et al., 2012). In contrast, workers from Eastern KSA, in their large series of 1590 patients, report a very high male to female ratio of 3.7:1 in their study (Al-Quorain et al., 2000). The age range of our study population was 4 to 75 years with a mean age 39.6 years; while the Nepalese study quotes similar figures of 2 years to 84 years (Rajbhandari et al., 2013). The Nigerian group has provided the age range of 2 to 87 years with a median of 59.5 years (Alatise et al., 2012); whereas from Eastern region of KSA, scientist have reported the age range from 6 to 81 years with a mean of 37 years; which is very close to that observed by us. Thus our findings are similar to the findings in the recent literature, regarding the sex and age parameters of the patients undergoing colonoscopy and colorectal biopsies.

Chronic nonspecific inflammation was the most common diagnosis in our study; reported in 360 patients ( $52.6 \%$ ); about $2 / 3$ being males. Chronic nonspecific inflammation or chronic inflammation, not otherwise specified (NOS) was also the most prevalent in many other studies. Nepalese workers found it in $27 \%$ of their 126 cases (Rajbhandari et al., 2013). Researchers from Jeddah, KSA reported chronic nonspecific inflammation in $25.4 \%$ of their 711 cases (Qayyum and Sawan, 2009). A large scale retrospective study from Eastern region of KSA also found nonspecific proctocolitis as most frequent diagnosis accounting for $37.4 \%$ of their cases (Al-Quorain et al., 2000). They also found that majority of these patients were males; and similar were the results from an earlier study from the same region, found mild to moderate non-specific colitis or proctitis in $28 \%$ of their 288 cases (Al-Freihi et al., 1986). Chronic nonspecific inflammation, most appropriately termed as chronic inflammation NOS, is considered as an inconclusive diagnosis. This microscopic picture may be due to a resolving or subclinical infection, any unrecognized injurious agents or a spectrum of quiescent IBD; and usually requires further investigations and/or follow-up.

In our study, ulcerative colitis (UC) was the second common diagnosis (217 cases, $31.7 \%$ of the total), followed by 22 cases, (3.2\% of the total) Crohn's disease (CD). UC affected slightly more males and more aged; whereas $\mathrm{CD}$ was predominant in females and younger patients. As we compare our IBD data with that of available recent publications; we find a Jamaican study of 103 patients, which report $64 \mathrm{UC}(62.1 \%)$ and $39 \mathrm{CD}$ cases $(27.9 \%)$, in contrast to our study female were more affected by UC and males more involved by CD (Penn et al., 2013). From Europe, workers from the North-East Romania have recently reported a frequency of $77 \% \mathrm{UC}$, with a higher age of onset averaging above 40 years in both UC and CD (Achitei et al., 2013). Almost similar results were reported from a recent population based Chinese study of 48 new cases $\{31$ UC (64.5\%) and 17 CD $(35.5 \%)$ cases $\}$ in one year. The median age of UC patients was higher (38 years), as compared to 25 years in CD patients (Zeng et al., 2013).

From the surrounding regions of KSA, a 100 IBD patients study from Bahrain, reported $82 \%$ UC, $16 \%$ $\mathrm{CD}$ and $2 \%$ Indeterminate IBD. Overall $55 \%$ were females and $59 \%$ were diagnosed between the ages of 20 to 40 years (Radhi \& Al-Qamish, 2011). A 200 IBD patients study from North-west Iran, report $91.5 \%$ UC and $8.5 \% \mathrm{CD}$ patients; with a mean ages at onset of 27 years for $\mathrm{CD}$ and 31.5 years for UC. There was a male dominance in both diseases (Masnadi Shirazi et al., 2013). Recent articles from within KSA report a variable data, for example in a 693 cases series from Riyadh, there were more CD $(65.7 \%)$ than UC $(34.3 \%)$ patients, both diseases occurred in younger age group than our study population; and males were predominantly affected in both the diseases (Al-Mofarreh \& Al-Mofleh, 2013). Another group of researchers from Central KSA, in their 312 IBD patients' series, have reported similarly with regards to more frequent $\mathrm{CD}$ and younger age involvement, however have observed a slight female preponderance (Fadda et al., 2012). Finally, Khawaja and Sawan (2009), from Western KSA, report $17.1 \%$ UC and only $2.1 \% \mathrm{CD}$, out of total 711 large bowel biopsies. Most of the cases were seen in the adolescence and adults, with age range of 1 to 40 years. 
The male to female ratio was 1.14:1 for UC and $0.87: 1$ for $\mathrm{CD}$ (37). This study results are more close to that observed by us. It is clear from citation of different studies from around the world and KSA, that there is wide variation in the demographics of IBD, most of them however showing $\mathrm{UC}$ to be more common than $\mathrm{CD}$ and prevailing in males; and our observations conform to these results.

In our study, ischemic bowel disease and diverticular disease were seen in $2.9 \%$ and $2.2 \%$ patients; while other less common conditions were eosinophilic colitis and solitary rectal ulcer, seen in $1.8 \%$ cases each. Regarding these less common diagnoses in our study, we could find similar brief mention in recent publications. However, a Danish study found diverticulosis and ischaemic colitis (23\% and $16 \%$ respectively) as the most common findings in their 163 patients of acute lower gastrointestinal bleeding (Hreinsson et al., 2013). On the other hand, in a large 1590 cases colonoscopy study from Eastern KSA, only $5.2 \%$ cases comprised of a miscellaneous group which included ischaemia, diverticular disease, eosinophilic colitis, tuberculosis, pseudomembranous colitis , polyps and lymphoma, etc (Al-Quorain et al., 2000). The Nigerian workers found 30 patients $(9.4 \%)$ of diverticular disease in their 320 cases of colonoscopy study (Alatise et al., 2012); whereas the Egyptian scientists found it in only $2 \%$ of their 864 patients (Elbatea et al., 2011). The study from Nepal included eosinophilic colitis in a general miscellaneous group of 19 cases $(15.1 \%)$ in their total 126 cases (Rajbhandari et al., 2013). As the number of cases diagnosed for these conditions is less, thus a conclusive comment is not possible, however our findings confirm with all the cited studies for the rarity of these conditions.

In our study results of more than six hundred cases, we observed that apart from the non-specific inflammations (NOS), IBD was the most frequent benign condition diagnosed in the colorectal biopsies. UC appears to be quite common; however a number of $\mathrm{CD}$ cases were also diagnosed. Ischaemic bowel disease and diverticular disease should also be considered in the differential diagnosis of colorectal biopsies in our region. Our findings are in conformity with the regional and national studies, especially the suggestion that IBD appears to be on a rise in our population; similar to the rising frequency of CRC as observed in other regional and national researches. This study has provided a baseline data for future folow-up studies. We therefore recommend follow-up studies, on the patients of IBD to investigate the link between IBD and $\mathrm{CRC}$ in the local population.

\section{References}

Achitei D, Gologan E, Stefănescu G, Balan G (2013). Clinical, biological and epidemiological aspects of inflammatory bowel diseases in North-East Romania. Rev Med Chir Soc Med Nat Iasi, 117, 16-22.

Adams SM, Bornemann PH (2013). Ulcerative colitis. Am Fam Physician, 87, 699-705.

Ahmad Z, Arshad H, Fatima S, et al (2013). Gastrointestinal, liver and biliary tract pathology: a histopathological and epidemiological perspective from Pakistan with a review of the literature. Asian Pac J Cancer Prev, 14, 6997-7005. Ahuja V, Tandon RK (2010). Inflammatory bowel disease in the Asia-Pacific area: a comparison with developed countries and regional differences. J Dig Dis, 11, 134-47.

Al-Freihi HM, Al-Idrissi HY, Al-Quorain A, et al (1986). The pattern of colonic diseases in the Eastern Province of Saudi Arabia. J Trop Med Hyg, 89, 23-7.

Al-Jashamy K, Murad A, Zeehaida M, Rohaini M, Hasnan J (2010). Prevalence of colorectal cancer associated with Streptococcus bovis among inflammatory bowel and chronic gastrointestinal tract disease patients. Asian Pac J Cancer Prev, 11, 1765-8.

Al-Mofarreh MA, Al-Mofleh IA (2013). Emerging inflammatory bowel disease in Saudi outpatients: a report of 693 cases. Saudi J Gastroenterol, 19, 16-22.

Al-Quorain AA, Satti MB, Al Gindan YM,Al-Hamdan A (2000). The pattern of lower gastrointestinal disease in the eastern region of Saudi Arabia: a retrospective analysis of 1590 consecutive patients. Saudi J Gastroenterol, 6, 27-32.

Alatise OI, Arigbabu AO, Agbakwuru EA, et al (2012). Spectrum of colonoscopy findings in Ile-Ife Nigeria. Niger Postgrad Med J, 19, 219-24.

Albasri A, Yosef H, Hussainy A, Bukhari S, Alhujaily A(2014a). Profile of colorectal polyps: a retrospective study from King Fahad Hospital, Madinah, Saudi Arabia. Asian Pac J Cancer Prev, 15, 2669-73.

Albasri A, Yosef H, Hussainy AS, Sultan SA, Alhujaily A (2014b). Histopathological features of colorectal cancer in Al-madinah region of Saudi Arabia: 8 years experience. Asian Pac J Cancer Prev, 15, 3133-7.

Azzam N, AljebreenAM, Alharbi O, Almadi MA (2013). Prevalence and clinical features of colonic diverticulosis in a Middle Eastern population. World J Gastrointest Endosc, 5,391-7.

Burisch J (2014). Crohn's disease and ulcerative colitis. Occurrence, course and prognosis during the first year of disease in a European population-based inception cohort. Dan Med J, 61, 4778.

Busch K, Ludvigsson JF, Ekstrom-Smedby K, et al (2014). Nationwide prevalence of inflammatory bowel disease in Sweden: a population-based register study. Aliment Pharmacol Ther, 39, 57-68.

Elbatea H, Enaba M, Elkassas G, El-Kalla F, Elfert AA (2011). Indications and outcome of colonoscopy in the middle of Nile delta of Egypt. Dig Dis Sci, 56, 2120-3.

Esmat S, El Nady M, Elfekki M, Elsherif Y, Naga M (2014). Epidemiological and clinical characteristics of inflammatory bowel diseases in Cairo, Egypt. World J Gastroenterol, 20, 814-21.

Fadda MA, Peedikayil MC, Kagevi I, et al (2012). Inflammatory bowel disease in Saudi Arabia: a hospital-based clinical study of 312 patients. Ann Saudi Med, 32, 276-82.

Faucheron JL, Roblin X, Bichard P, Heluwaert F (2013). The prevalence of right-sided colonic diverticulosis and diverticular haemorrhage. Colorectal Dis, 15, 266-70.

Ghosh S, Almadi MA (2013). Inflammatory Bowel Disease : A Global Disease. Saudi J Gastroenterol, 19, 1-2.

Golovics PA, Mandel MD, Lovasz BD, Lakatos PL (2014). Inflammatory bowel disease course in Crohn's disease: Is the natural history changing? World J Gastroenterol, 20, 3198-207.

Hreinsson JP, Gumundsson S, Kalaitzakis E, Bjornsson ES (2013). Lower gastrointestinal bleeding: incidence, etiology, and outcomes in a population-based setting. Eur $J$ Gastroenterol Hepatol, 25, 37-43.

Huai JP, Ding J, Ye XH, Chen YP (2014). Inflammatory bowel disease and risk of cholangiocarcinoma: evidence from 
a meta-analysis of population-based studies. Asian Pac $J$ Cancer Prev, 15, 3477-82.

Kasturiratne A, Mufeena MN, Mettananda KC, et al (2014). Incidence of inflammatory bowel disease in Gampaha district: details of the Sri Lankan component of the AsiaPacific Crohn's and Colitis Epidemiology Study. Ceylon Med J, 59, 16-8.

Khawaja AQ, Sawan AS (2009). Inflammatory bowel disease in the Western Saudi Arabia. Saudi Med J, 30, 537-40.

Klarin I, Majnaric L, Jovanovic Z, et al (2013). Epidemiology and clinical presentation of inflammatory bowel disease in Zadar County, Croatia. Coll Antropol, 37, 1161-70.

Ko Y, Butcher R, Leong RW (2014). Epidemiological studies of migration and environmental risk factors in the inflammatory bowel diseases. World J Gastroenterol, 20, 1238-47.

Lakatos L, Kiss LS, David G, et al (2011). Incidence, disease phenotype at diagnosis, and early disease course in inflammatory bowel diseases in Western Hungary, 20022006. Inflamm Bowel Dis, 17, 2558-65.

Liu W, Zeng HZ, Wang QM, et al (2013). Schistosomiasis combined with colorectal carcinoma diagnosed based on endoscopic findings and clinicopathological characteristics: a report on 32 cases. Asian Pac J Cancer Prev, 14, 4839-42.

Mangat BK, Evaschen C, Lee T, Yoshida EM, Salh B (2011). Ethnic variation in the annual rates of adult inflammatory bowel disease in hospitalized patients in Vancouver, British Columbia. Can J Gastroenterol, 25, 73-7.

Masnadi Shirazi K, Somi MH, Bafandeh Y, et al (2013). Epidemiological and clinical characteristics of inflammatory bowel disease in patients from northwestern Iran. Middle East J Dig Dis, 5, 1-5.

Molodecky NA, Soon IS, Rabi DM, et al (2012). Increasing incidence and prevalence of the inflammatory bowel diseases with time, based on systematic review. Gastroenterology, 142, 46-54.

Mosli MH, Feagan BG, Sandborn WJ, et al (2014). Histologic evaluation of ulcerative colitis: a systematic review of disease activity indices. Inflamm Bowel Dis, 20, 564-75.

$\mathrm{Ng} \mathrm{SC}$, Tang W, Ching JY, et al (2013). Incidence and phenotype of inflammatory bowel disease based on results from the Asia-Pacific Crohn's and Colitis Epidemiology Study. Gastroenterology, 145, 158-65.

Nguyen GC, Chong CA, Chong RY (2014). National estimates of the burden of inflammatory bowel disease among racial and ethnic groups in the United States. J Crohns Colitis, 8, 288-95.

Norgard BM, Nielsen J, Fonager K, et al (2014). The incidence of ulcerative colitis (1995-2011) and Crohn's disease (19952012) - Based on nationwide Danish registry data. J Crohns Colitis, pii, 1873-946.

Penn KA, Whittle DO, Lee MG (2013). Inflammatory bowel disease in Jamaica. Ann Gastroenterol, 26, 239-42.

Ponder A, Long MD (2013). A clinical review of recent findings in the epidemiology of inflammatory bowel disease. Clin Epidemiol, 5, 237-47.

Qayyum A, Sawan AS (2009). Profile of colonic biopsies in King Abdul Aziz University Hospital, Jeddah. J Pak Med Assoc, 59, 608-11.

Radhi QR, Al-Qamish JR (2011). Inflammatory bowel disease: a retrospective study. Bahrain Medical Bulletin, 33, 1-10.

Rajbhandari M, Karmacharya A, Khanal K, Dhakal P, Shrestha R (2013). Histomorphological profile of colonoscopic biopsies and pattern of colorectal carcinoma in Kavre district. Kathmandu Univ Med J, 11, 196-200.

Ren LL, Fang JY (2011). Should we sound the alarm? Dysplasia and colitis-associated colorectal cancer. Asian Pac J Cancer Prev, 12, 1881-6.
Safarpour AR, Hosseini SV, Mehrabani D (2013). Epidemiology of inflammatory bowel diseases in Iran and Asia; a mini review. Iran J Med Sci, 38, 140-9.

Siddique I, Alazmi W, Al-Ali J, et al (2012). Clinical epidemiology of Crohn's disease in Arabs based on the Montreal Classification. Inflamm Bowel Dis, 18, 1689-97.

Soliman NA, Keshk WA, Shoheib ZS, Ashour DS, Shamloula MM (2014). Inflammation, oxidative stress and L-fucose as indispensable participants in schistosomiasis-associated colonic dysplasia. Asian Pac J Cancer Prev, 15, 1125-31.

Villafuerte-Galvez J, Sotelo-Olivera MI, Cok J, Piscoya-Rivera A, Huerta-Mercado J (2012). Colonoscopic findings in Peruvian patients with chronic diarrhea. PLoS One , 7, 46690.

Wei SC, Lin MH, Tung CC, et al (2013) . A nationwide population-based study of the inflammatory bowel diseases between 1998 and 2008 in Taiwan. BMC Gastroenterol, $13,166$.

Zeng Z, Zhu Z, Yang Y, et al (2013). Incidence and clinical characteristics of inflammatory bowel disease in a developed region of Guangdong Province, China: a prospective population-based study. J Gastroenterol Hepatol, 28, 1148-53.

Zhao J, Ng SC, Lei Y, et al (2013). First prospective, populationbased inflammatory bowel disease incidence study in mainland of China: the emergence of "western" disease. Inflamm Bowel Dis, 19, 1839-45. 